Ambiente \& Água - An Interdisciplinary Journal of Applied Science
ISSN 1980-993X - doi:10.4136/1980-993X
www.ambi-agua.net
E-mail: ambi.agua@gmail.com

\title{
Análise das condições de potabilidade das águas de surgências em Ubá, MG
}

\author{
doi: 10.4136/ambi-agua.1630
}

Received: 28 Mar. 2015; Accepted: 26 May 2015

\author{
José Antonio Rodrigues de Souza ${ }^{1 *}$; Débora Astoni Moreira ${ }^{2}$; \\ Naiara Moreira Condé ${ }^{3}$; Wanderbeth Belchior de Carvalho ${ }^{1}$; \\ Christina Vargas Miranda e Carvalho ${ }^{2}$ \\ ${ }^{1}$ Instituto Federal Goiano (IFGoiano), Urutaí, GO, Brasil \\ Departamento de Engenharia Agrícola \\ ${ }^{2}$ Instituto Federal Goiano (IFGoiano), Urutaí, GO, Brasil \\ Departamento de Química \\ ${ }^{3}$ Universidade Estadual de Minas Gerais (UEMG), Ubá, MG, Brasil \\ Departamento de Química \\ *Autor correspondente: e-mail: jarstec@yahoo.com.br, \\ deboraastoni@yahoo.com.br, naiaraconde@ hotmail.com, \\ betocarvalho2014@gmail.com, chrisvmirandac@gmail.com
}

\section{RESUMO}

No presente trabalho, objetivou-se estudar a interferência das atividades antrópicas nas condições de potabilidade das águas subterrâneas localizadas no perímetro urbano do município de Ubá, MG. Para isso, dez surgências tiveram suas características físicas (temperatura, turbidez e cor), químicas ( $\mathrm{pH}$, condutividade elétrica, cloreto, dureza e nitrato) e microbiológicas (coliformes totais e termotolerantes) monitoradas ao longo de um ano. Os parâmetros temperatura, $\mathrm{pH}$ e cor, cloreto e dureza de todas as surgências monitoradas foram consideradas normais em relação ao padrão de potabilidade. Já a análise de turbidez, condutividade elétrica, nitrato e coliformes totais e termotolerantes indicaram contaminação por atividades antropogênicas. De maneira geral, os resultados indicaram ocorrência de elevada degradação ambiental, onde apenas 30\% das surgências monitoradas atenderam os padrões de potabilidade, sendo, portando, necessárias intervenções no sentido de garantir sua qualidade.

Palavras-chave: poluição, qualidade da água, recursos hídricos.

\section{Analysis of potability conditions of upwelling water in Ubá, MG}

\begin{abstract}
In this work we investigated the interference of anthropic activities on the potability of groundwater in the urban area of the city of Ubá, MG. To accomplish this, the physical characteristics (temperature, turbidity and color), chemical ( $\mathrm{pH}$, conductivity, chloride, nitrate and hardness) and microbiological (total and thermotolerant coliforms) of ten upwelling waters were monitored throughout one year. The temperature, $\mathrm{pH}$, color, chloride and hardness of all upwelling waters were considered normal compared to standards of potable water. However, the analyses of turbidity, electrical conductivity, nitrate and total and
\end{abstract}


thermotolerant coliforms indicate contamination by human activities. Overall, the results indicated the occurrence of high environmental degradation, where only $30 \%$ of monitored upwelling waters were in accordance with the quality standard, indicating the need for intervention to ensure water quality.

Keywords: pollution, water quality, water resources.

\section{INTRODUÇÃO}

O aumento da demanda por água nas cidades, associada aos impactos da rápida urbanização, conduz a um quadro preocupante em relação ao futuro da sustentabilidade do abastecimento público urbano, especialmente em algumas regiões metropolitanas brasileiras.

No Brasil, cerca de $40 \%$ dos municípios são abastecidos por água subterrânea e, várias cidades suprem todas as suas necessidades hídricas utilizando esse tipo de abastecimento que, além de atender diretamente à população, são utilizados na indústria, agricultura, lazer entre outras (Suhogusoff, 2013; Hirata et al., 2011; ANA, 2010). Já em Minas Gerais, 70\% dos municípios utilizam água subterrânea no sistema de abastecimento, sendo $9 \%$ captadas em poços rasos e os $61 \%$ restantes, são provenientes de poços profundos (IBGE, 2008).

Apesar da sua expressiva contribuição para o desenvolvimento socioeconômico de muitas regiões do país e do seu papel ecológico na manutenção do fluxo de base dos corpos de hídricos, a gestão da água subterrânea ainda é incipiente e não reflete sua relevância atual e estratégica. A falta de políticas públicas para o setor mostra-se na lacuna de conhecimento do estágio de utilização e das potencialidades dos aquíferos, bem como dos riscos de contaminação antropogênica a que estão submetidos e que afetam sua qualidade (Hirata et al., 2011). A redução da quantidade e a degradação da qualidade da água afetam a sociedade como um todo (Menezes et al., 2013; Nakamura et al., 2014).

A qualidade da água tanto superficial como subterrânea, destinadas ao consumo humano deve atender a padrões de qualidade e de potabilidade, garantindo que suas características físicas, químicas e biológicas estejam dentro dos padrões recomendados pela Organização Mundial da Saúde (OMS). No Brasil, os padrões de potabilidade são definidos na Portaria $\mathrm{n}^{\circ}$ 2914 de 2011 do Ministério da Saúde (Brasil, 2011), enquanto a qualidade de águas superficiais para os diferentes usos são estabelecidos pela resolução CONAMA n ${ }^{\circ} 357$ de 2005 (CONAMA, 2005).

A poluição provocada pelas atividades humanas, o aumento da população mundial, o consumo excessivo e o alto grau de desperdício são fatores que colocam em risco a disponibilidade de água doce. Por sua importância estratégica para as gerações presentes e futuras, nossas reservas de água subterrânea necessitam de um cuidado especial, para sua preservação e utilização de forma sustentável.

Considerando a grande importância das águas subterrâneas para a manutenção e expansão do desenvolvimento urbano e a possibilidade de contaminação por doenças de veiculação hídrica, neste trabalho objetivou-se estudar a interferência das atividades antrópicas nas condições de potabilidade das águas subterrâneas localizadas em um trecho urbano da bacia do ribeirão Ubá-MG.

\section{MATERIAL E MÉTODOS}

O estudo foi conduzido em um trecho urbano da bacia do ribeirão Ubá (ou ribeirão Miragaia), pertencente à bacia do Rio Paraíba do Sul, cuja extensão de $33 \mathrm{~km}$ é responsável pela drenagem de uma área de $254 \mathrm{~km}^{2}$, que corresponde a 62,3\% da área do município de Ubá-MG (Ubá, 2011). 
Os solos predominantes na região são do tipo argiloso, apresentando $55 \%$ do relevo ondulado e $40 \%$ montanhoso, com altitudes variando entre $300 \mathrm{~m}$ (região Sul do município) e $900 \mathrm{~m}$ (região Nordeste do município). A precipitação média anual é de $1.272 \mathrm{~mm}^{2} \mathrm{ano}^{-1}$, tendo como época de chuvas abundantes o período compreendido entre os meses de outubro, novembro, dezembro e janeiro, sendo que nos meses de julho e agosto, há uma deficiência hídrica anual de $100 \mathrm{~mm}$. Já em relação às temperaturas médias, o mês de junho apresenta valores mínimos em torno de $19^{\circ} \mathrm{C}$ e, em março, ocorrem aos valores máximos, em torno de $31^{\circ} \mathrm{C}$ (Ubá, 2011).

A cidade de Ubá possui uma população estimada em 109.779 habitantes e tem como principal atividade econômica a fabricação de móveis (IBGE, 2014). Apesar de $84 \%$ dos domicílios possuírem acesso à rede de abastecimento de água, apenas $67 \%$ deles têm acesso a rede coleta de esgoto (DATASUS, 2014; SNIS, 2013), os quais, apesar de serem coletados, são lançados diretamente nos cursos de água da região, principalmente no ribeirão Ubá, sem nenhum tipo de tratamento (Antunes, 2015; Ubá, 2011).

O esgoto doméstico e comercial representa cerca de $80 \%$ do volume total de efluentes lançados no ribeirão ubá. Porém, os cerca de $20 \%$ referentes ao esgoto industrial, sobretudo da indústria moveleira, tinturaria e galvanoplastia, representam a carga de esgoto com maior impacto sobre a qualidade das águas (IGAM, 2013; Ubá, 2011). No que se refere a coleta de resíduos sólidos, apesar de $98 \%$ da população ser atendida, o município não conta com sistema de disposição final, exportando seus resíduos domiciliares para a cidade de Juiz de Fora, MG, localizada a 111 km de distância (SNIS, 2013).

Para avaliação dos efeitos da ação antrópica sobre as condições de podtabilidade das águas subterrâneas, dez surgências tiveram suas características físicas, químicas e microbiológicas monitoradas ao longo do ano de 2014, em avaliações bimestrais. Na Figura 1, está apresenta a localização geográfica dos pontos de monitoramento (em coordenadas UTM, com datum cartográfico SAD-69, zona 23 k), correspondente às surgências localizadas nos diferentes bairros ao longo do ribeirão Ubá, quais sejam, Fazendinha, Cibraci, Primavera, Eldorado, Bom Pastor, Paulino Fernandes, Caxangá, São Judas Tadeu, Sobradinho e Altair Rocha. A população local tem o hábito de captar água de tais nascentes por não confiar no sistema de tratamento de água, todavia, tais fontes de água estão sendo impactadas pelo mau uso e ocupação do solo, que ocorrem sem a preocupação de preservação da mata ciliar, bem como pelo lançamento de efluentes nos mananciais próximos.

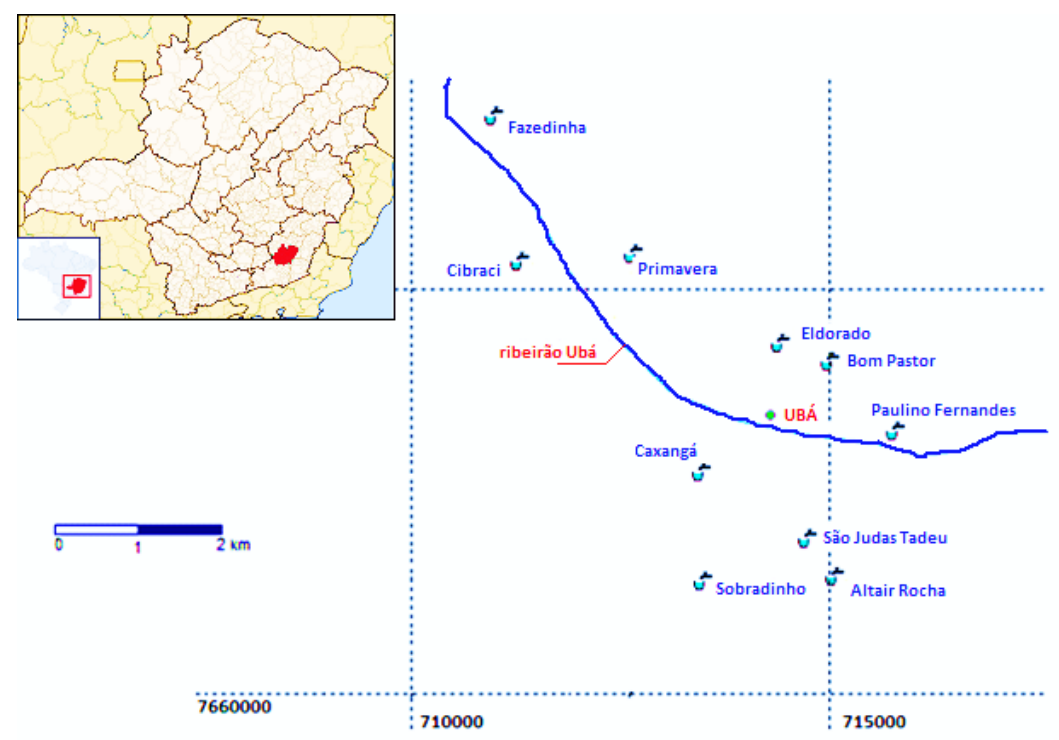

Figura 1. Localização geográfica das surgências monitoradas ao longo do ribeirão Ubá. 
As determinações dos valores de temperatura e $\mathrm{pH}$ foram realizadas "in situ" utilizandose os métodos de laboratório e eletrométrico (códigos APHA 4500- $\mathrm{H}^{+} \mathrm{B}$ e 2550B) respectivamente, enquanto para as demais características, amostras de água foram coletadas em frascos previamente esterilizados, acondicionadas em caixa térmica contendo gelo, sendo conduzidas, imediatamente, ao Laboratório de Análise de Água (LANAG) da Universidade do Estado de Minas Gerais - Unidade Ubá. Nestas amostras foi realizada a determinação da turbidez pelo método nefelométrico (2130B), da cor pelo método visual de comparação (2120B), da condutividade elétrica pelo método de laboratório (2510B), de cloreto pelo método argentimétrico (4500-Cl-B), da dureza total pelo método titulométrico com EDTA $(2340 \mathrm{C})$, de nitrato $\left(\mathrm{N}-\mathrm{NO}_{3}{ }^{-}\right)$pelo método de redução do cádmio $\left(4500-\mathrm{NO}_{3}{ }^{-} \mathrm{E}\right)$ e coliformes totais e termotolerantes pelo método de substrato enzimático (9223A, B: parte 9000 e 9223: parte 9000, respectivamente), segundo metodologias descritas em APHA et al. (2012).

\section{RESULTADOS E DISCUSSÃO}

Os valores médios e respectivos desvios-padrão das características físicas, químicas e microbiológicas nas dez surgências monitoradas ao longo do ano de 2014 estão apresentados na Tabela 1.

Tabela 1. Valores médios e respectivos desvios-padrão das características físicas e químicas da água das surgências monitoradas no perímetro urbano de Ubá, MG

\begin{tabular}{|c|c|c|c|c|c|c|c|c|}
\hline \multirow{2}{*}{ Surgências } & \multirow{2}{*}{$\mathrm{pH}$} & $\mathrm{T}$ & Turbidez & Cor & $\mathrm{CE}$ & Cloreto & Dureza & $\mathrm{N}-\mathrm{NO}_{3}{ }^{-}$ \\
\hline & & ${ }^{\circ} \mathrm{C}$ & UNT & $\mathrm{uH}$ & $\mu \mathrm{S} \mathrm{cm}^{-1}$ & $\mathrm{mg} \mathrm{L}^{-1}$ & $\mathrm{mg} \mathrm{L}^{-1}$ & $\mathrm{mg} \mathrm{L}^{-1}$ \\
\hline Bom Pastor & $7,66 \pm 0,17$ & $22,4 \pm 2,06$ & $0,04 \pm 0,02$ & $5,90 \pm 0,80$ & $107,6 \pm 6,50$ & $19,3 \pm 0,73$ & $53,0 \pm 3,74$ & $0,748 \pm 0,080$ \\
\hline Eldorado & $7,42 \pm 0,11$ & $22,4 \pm 2,06$ & $8,30 \pm 1,40$ & $9,51 \pm 1,10$ & $101,2 \pm 8,04$ & $28,8 \pm 1,94$ & $33,6 \pm 2,94$ & $2,661 \pm 0,240$ \\
\hline Primavera & $7,19 \pm 0,15$ & $22,4 \pm 2,06$ & $0,04 \pm 0,02$ & $3,75 \pm 0,80$ & $63,6 \pm 7,05$ & $28,8 \pm 1,94$ & $10,2 \pm 1,33$ & $3,930 \pm 0,070$ \\
\hline Cibraci & $7,00 \pm 0,06$ & $22,4 \pm 2,06$ & $0,04 \pm 0,02$ & $4,75 \pm 0,50$ & $21,5 \pm 5,82$ & $28,8 \pm 1,94$ & $2,6 \pm 1,20$ & $0,264 \pm 0,010$ \\
\hline Sobradinho & $7,30 \pm 0,08$ & $24,0 \pm 2,76$ & $0,04 \pm 0,02$ & $6,87 \pm 0,70$ & $63,9 \pm 4,26$ & $28,8 \pm 1,94$ & $24,0 \pm 2,19$ & $0,469 \pm 0,030$ \\
\hline $\begin{array}{l}\text { Altair } \\
\text { Rocha }\end{array}$ & $7,38 \pm 0,10$ & $24,0 \pm 2,76$ & $0,04 \pm 0,02$ & $5,89 \pm 0,70$ & $53,4 \pm 5,38$ & $28,8 \pm 1,94$ & $16,6 \pm 1,20$ & $1,365 \pm 0,150$ \\
\hline $\begin{array}{l}\text { São Judas } \\
\text { Tadeu }\end{array}$ & $7,30 \pm 0,09$ & $22,4 \pm 2,06$ & $0,04 \pm 0,02$ & $7,32 \pm 0,50$ & $42,5 \pm 4,44$ & $19,5 \pm 2,57$ & $14,0 \pm 1,67$ & $1,478 \pm 0,130$ \\
\hline Fazendinha & $6,19 \pm 0,15$ & $21,6 \pm 1,74$ & $14,72 \pm 1,23$ & $12,30 \pm 1,20$ & $105,6 \pm 6,07$ & $21,7 \pm 2,22$ & $22,4 \pm 1,50$ & $4,552 \pm 0,440$ \\
\hline Caxangá & $6,42 \pm 0,08$ & $21,6 \pm 1,74$ & $0,04 \pm 0,02$ & $4,30 \pm 0,50$ & $176,4 \pm 6,68$ & $35,4 \pm 2,92$ & $44,6 \pm 2,80$ & $5,265 \pm 0,360$ \\
\hline $\begin{array}{l}\text { Paulino } \\
\text { Fernandes }\end{array}$ & $6,62 \pm 0,10$ & $20,6 \pm 1,74$ & $11,9 \pm 1,59$ & $10,25 \pm 1,20$ & $49,9 \pm 6,15$ & $21,9 \pm 1,89$ & $21,8 \pm 1,83$ & $0,345 \pm 0,030$ \\
\hline
\end{tabular}

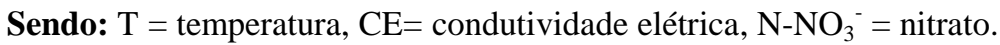

A temperatura é um dos padrões, ou características organolépticas, de qualidade das águas atrelada à sensibilidade dos organismos vivos, que tornam uma água atraente ou não para o consumo. Quando a alteração da temperatura de um corpo hídrico é tão significativa a ponto de alterar a sua qualidade, a mesma passa a ser caracterizada como poluição térmica (Percebon, 2005).

As temperaturas observadas $\left(20,6^{\circ}-24^{\circ} \mathrm{C}\right)$ não refletiram qualquer atividade antrópica que estivesse ocorrendo nas águas, verificando-se apenas uma elevação de seus níveis em virtude do incremento da temperatura do ar ao longo das coletas, visto que o município 
apresenta clima tropical úmido, com temperatura média anual variando entre $18^{\circ} \mathrm{C}$ e $24^{\circ} \mathrm{C}$ (Ubá, 2011).

A faixa de pH observada $(6,19$ - 7,66) é considerada normal, estando em concordância com o padrão de qualidade de águas superficiais da Resolução CONAMA no 357/2005 e, de potabilidade, conforme Portaria $n^{\circ}$ 2.914/2011 do Ministério da Saúde, não sendo evidenciado um padrão espacial de ocorrência. Estes resultados estão de acordo com os estudos de qualidade das águas superficiais do ribeirão Ubá realizados por Carvalho et al. (2004) e, isoladamente, não indicam quaisquer efeitos da ação humana na qualidade das águas.

As surgências localizadas nos bairros Eldorado, Fazendinha e Paulino Fernandes apresentaram valores médios de turbidez acima do padrão de aceitação para consumo humano sem tratamento prévio, conforme Portaria $n^{\circ}$ 2914/2011 do Ministério da Saúde, que estabelece o limite de 5 UNT, em complementação às exigências microbiológicas.

Embora a turbidez possa ter origem natural, não trazendo inconvenientes sanitários diretos, esteticamente é desagradável na água potável, e os sólidos em suspensão podem servir de abrigo para microrganismos patogênicos (Perpétuo, 2014; Von Sperling, 2005). No caso das surgências em questão, os valores observados podem estar relacionados tanto as causas naturais, como o mau uso do solo, como antrópicas, pela contaminação por esgotos sanitários.

Com relação ao abastecimento público de água, a cor, embora seja um atributo estético, não se relacionando, necessariamente, com problemas de contaminação, é padrão de potabilidade (Perpétuo, 2014). A presença de cor provoca repulsa psicológica pelo consumidor devido a associação com a descarga de esgotos. Os valores de cor para todas as surgências monitoradas foram inferiores $15 \mathrm{uH}$, sendo considerada como potável, segundo critério estabelecido pela Portaria no 2914/2011 do Ministério da Saúde.

Segundo CETESB (2010), a condutividade elétrica representa uma medida indireta do efeito antrópico, já que depende das concentrações iônicas e da temperatura, indicando a quantidade de sais existentes na água. Dessa forma, as surgências localizadas em Bom Pastor, Eldorado, Fazendinha e Caxangá apresentaram valores para o parâmetro condutividade elétrica acima de $100 \mu \mathrm{S} \mathrm{cm}^{-1}$, indicando ambientes impactados, conforme (CETESB, 2010)

Em relação às propriedades organolépticas de potabilidade analisadas, tanto os valores do cloreto, como de dureza de todas as surgências monitoradas estão dentro dos limites estabelecidos pelo Ministério da Saúde, conforme Portaria n 2914/2011.

Resultados semelhantes foram obtidos por Carvalho et al. (2004), quanto analisaram as águas superficiais do ribeirão Ubá que percorria todo o trecho urbano, inclusive nas proximidades do lançamento de efluentes industrial. Também, Silva e Araújo (2002), ao analisarem amostras de água do manancial subterrâneo em Feira de Santana (BA), com muitos trechos sabidamente poluídos, obtiveram 100\% das amostras com parâmetros de cloretos e dureza dentro do padrão recomendado. Estes autores concluíram que tais parâmetros necessitam de elevada concentração para indicarem alteração na qualidade das águas.

A presença de compostos de nitrogênio nos seus diferentes estados de oxidação é indicativo de contaminação do aquífero e de possíveis condições higiênico-sanitárias insatisfatórias. $\mathrm{O}$ nitrato em excesso provoca dois efeitos adversos à saúde, quais sejam, a indução à metemoglobinemia, especialmente em crianças e, a formação potencial de nitrosaminas e nitrosamidas, ambas carcinogênicas (Scorsafava et al., 2010; Nascimento e Barbosa, 2005). Por isso, apesar do valor máximo permitido estabelecido pela Portaria $\mathrm{n}^{\circ}$ 2914/2011 do Ministério da Saúde ser de $10 \mathrm{mg} \mathrm{L}^{-1} \mathrm{~N}_{-} \mathrm{NO}_{3}$ na água potável, valores superiores a $3 \mathrm{mg} \mathrm{L}^{-1}$ já considerado que a fonte de água está sendo contaminada (Cordeiro et al., 2011).

Dessa forma, analisando a Tabela 1, constata-se que o consumo das águas das surgências "in natura" não provocaria tais enfermidades. Todavia, no que concerne a contaminação por 
atividades antropogênicas, as surgências localizadas em Eldorado, Primavera, Fazendinha e Caxangá, ou seja, 30\% das fontes de água apresentaram concentrações $\mathrm{N}_{-} \mathrm{NO}_{3}{ }^{-}$superiores a $3 \mathrm{mg} \mathrm{L}^{-1}$, o que configura, segundo Cordeiro et al. (2011), que estas fontes de água estão contaminadas.

Scorsafava et al. (2010) estudando a qualidade de água de poços e surgências destinadas ao consumo humano no estado de São Paulo, verificaram que a concentração de nitrato foi superior ao permitido pela legislação em $15 \%$ dos poços e $30 \%$ das surgências. Resultados semelhantes foram obtidos por Freitas et al. (2001) ao analisarem amostras de águas de poços no Parque Fluminense, no Rio de Janeiro, que obtiveram 30\% das amostras com valores superiores ao máximo permitido pela legislação.

$\mathrm{Na}$ Tabela 2 estão apresentadas as médias geométricas das características microbiológicas da água das surgências monitoradas.

Tabela 2. Valores médios e respectivos desvios-padrão das características microbiológicas da água das surgências monitoradas no perímetro urbano de Ubá, MG.

\begin{tabular}{lll}
\hline \multirow{2}{*}{ Surgências } & \multicolumn{1}{c}{ CT } & \multicolumn{1}{c}{ CF } \\
\cline { 2 - 3 } & \multicolumn{2}{c}{$\mathrm{NMP} / 100 \mathrm{~mL}$} \\
\hline Bom Pastor & $7,5 \pm 1,3$ & $<1^{*}$ \\
Eldorado & $201,2 \pm 13,9$ & $24,1 \pm 1,6$ \\
Primavera & $<1^{*}$ & $<1^{*}$ \\
Cibraci & $<1^{*}$ & $<1^{*}$ \\
Sobradinho & $<1^{*}$ & $<1^{*}$ \\
Altair Rocha & $104,0 \pm 9,5$ & $20,0 \pm 0,9$ \\
São Judas Tadeu & $18,9 \pm 1,8$ & $4,1 \pm 0,5$ \\
Fazendinha & $10.167,0 \pm 270,0$ & $1.512,5 \pm 76,0$ \\
Caxangá & $162,4 \pm 12,0$ & $<1^{*}$ \\
Paulino Fernandes & $6.878,0 \pm 145,0$ & $998,5 \pm 53,0$ \\
\hline
\end{tabular}

Sendo: CT - coliformes totais, CF - coliformes termotolerantes, NMP - número mais provável.

* limite inferior de detecção do método.

A determinação da concentração dos coliformes assume importância como parâmetro indicador da possibilidade da existência de microrganismos patogênicos, responsáveis pela transmissão de doenças de veiculação hídrica. Já a presença de coliformes fecais indica a possibilidade de ocorrência de outros microrganismos patogênicos entéricos na água e a possibilidade de contaminação fecal (Moura et al., 2009; Silva, 2000). Segundo Portaria $\mathrm{n}^{\circ}$ 2914/2011 do Ministério da Saúde, em termos microbiológicos, a potabilidade da água pode ser determinada pela ausência de contagem de coliformes totais e termotolerantes em $100 \mathrm{~mL}$ de amostra.

Observando-se a Tabela 2, verifica-se que as surgências localizadas em Bom Pastor, Eldorado, Altair Rocha, São Judas Tadeu, Fazendinha, Caxangá e Paulino Fernandes, ou seja, $70 \%$ das fontes de água, não apresentaram condições de serem consumidas "in natura", sendo necessário um processo de desinfecção a fim de torna-las aptas ao consumo, devido ao alto grau de contaminação.

Resultados semelhantes foram obtidos por Lima e Freitas (2007) ao estudarem a qualidade das águas de poços e nascentes no perímetro urbano do município de Uberaba, consumidas por uma parcela da população. Estes autores constataram que $40 \%$ dos poços e 
$75 \%$ das surgências apresentavam águas impróprias para consumo humano, estando em desacordo com os padrões legais vigentes e exigidos pela Portaria $n^{\circ} 2915 / 2011$. No que se refere ao ribeirão em estudo, Carvalho et al. (2004), verificaram que as águas superficiais do ribeirão Ubá que banhavam o perímetro urbano apresentavam-se contaminadas por coliformes totais e termotolerantes.

Considerando-se os parâmetros monitorados, constatou-se que apenas 30\% surgências monitoradas apresentaram-se adequadas ao consumo "in natura", conforme padrões de potabilidade, indicando que a região vem sofrendo tanto com o mau uso e ocupação do solo, como pelo descarte de efluentes nos mananciais da região sem nenhum tipo de tratamento, provando forte degradação ambiental e elevado risco de contaminação por doenças de veiculação hídrica. Assim, torna-se necessária a intervenções do poder público no sentido de disciplinar a ocupação da região, conciliando-se urbanização e preservação, por meio do zoneamento ambiental, bem como investimentos no saneamento público, sobretudo no que se refere ao tratamento dos efluentes coletados e despejados nos mananciais da região sem nenhum tratamento.

A qualidade das fontes de água monitorada está diretamente associada às características de sua localização, tais como reduzida infraestrutura sanitária, erosão do solo, proximidade dos pontos de lançamento de efluentes, e inadequado estado de preservação das surgências. Dessa forma, embora o município tenha o privilégio de dispor de elevadas fontes de água, tanto as fontes subterrâneas, como as superficiais, estão sofrendo com a poluição por efluentes domésticos e industriais, tornando-se necessárias intervenções no sentido de garantir qualidade e quantidade de água para as atuais e futuras gerações.

\section{CONCLUSÃO}

De acordo com os resultados encontrados, pode-se concluir que apenas $30 \%$ das surgências monitoradas apresentaram-se aptas para consumo "in natura", segundo os padrões de potabilidade, indicando que as fontes de água subterrânea na região vêm sofrendo com a degradação ambiental, sendo necessárias intervenções no sentido de garantir sua qualidade.

\section{REFERENCIAS}

AMERICAN PUBLIC HEALTH ASSOCIATION -APHA; AMERICAN WATER WORKS ASSOCIATION - AWWA; WATER ENVIRONMENT FEDERATION - WEF. Standard methods for the examination of water and wastewater. 22 ed. New York, 2012. 1496p.

AGENCIA NACIONAL DE ÁGUAS - ANA (Brasil). Atlas Brasil. Abastecimento urbano de água: panorama nacional. Brasília, 2010. 72p.

ANTUNES, C. MP pede que Prefeitura de Ubá, MG, comece a tratar o esgoto da cidade. Disponível em: <http://g1.globo.com/mg/zona-da-mata/noticia/2015/04/mp-pede-queprefeitura-de-uba-mg-comece-tratar-o-esgoto-da-cidade.html>. Acesso em: 20 fevereiro 2015.

BRASIL. Ministério da Saúde. Portaria no .2914 de 12 de dezembro de 2011. Dispõe sobre os Procedimentos e Responsabilidades Relativos ao Controle e Vigilância da Qualidade da Água para Consumo Humano e seu Padrão de Potabilidade. Diário Oficial [da] União, Brasília, 14 dez. 2011. 
BRASIL. Ministério das Cidades. Secretaria Nacional de Saneamento Ambiental - SNIS. Sistema Nacional de Informações sobre Saneamento. 2013. Disponível em <http://www.cidades.gov.br/serieHistorica/>. Acesso em: 20 fevereiro 2015.

CARVALHO, C. F.; FERREIRA, A. L.; STAPELFELDT, F. Qualidade das águas do ribeirão Ubá - MG. Revista Escola de Minas. v. 57, n. 3, p.165-172, 2004.

COMPANHIA AMBIENTAL DO ESTADO DE SÃO PAULO - CETESB. Variáveis da qualidade de água. Disponível em: <http://www.cetesb.sp.gov.br/agua/aguassuperficiais/109-variaveis-de-qualidade-das-aguas>. Acesso em: 20 fevereiro 2015.

CONSELHO NACIONAL DO MEIO AMBIENTE - CONAMA (Brasil). Resolução n 357, de 17 de março de 2005. Dispõe sobre a classificação dos corpos de água e diretrizes ambientais para o seu enquadramento, bem como estabelece as condições e padrões de lançamento de efluentes, e dá outras providências. Alterado pela Resolução CONAMA 397/2008. Disponível em: <http://www.mma.gov.br/conama>. Acesso em: 20 fevereiro 2015 .

CORDEIRO, M. R.; RODRIGUES, S. M.; SOUZA, P. R. N.; FERREIRA, M. I. P. Avaliação da contaminação de efluentes domésticos em poços sobre área de restinga. Boletim do Observatório Ambiental Alberto Ribeiro Lamego, Campos dos Goytacazes, v. 5, n. 1, p.89-102, 2011.

DATASUS. Sistema de Informação de Atenção Básica. Situação de Saneamento - Brasil. 2014. Disponível em: <http://tabnet.datasus.gov.br/cgi/deftohtm.exe?siab/cnv/SIABCbr. def> Acesso em: 10 fevereiro 2015.

FREITAS, M. B.; BRILHANTE, O. M.; ALMEIDA, L. M. Importância da análise de água para a saúde pública em duas regiões do Estado do Rio de Janeiro: enfoque para coliformes fecais, nitrato e alumínio. Caderno Saúde Pública, Rio de Janeiro. v. 17, n. 3, p.651-660, 2001. http://dx.doi.org/10.1590/S0102-311X2001000300019

HIRATA, R; ZOBBI, J.; OLIVEIRA, F. Águas subterrâneas: reserva estratégica ou emergencial. In: BICUDO, C. E. M.; TUNDISI, J. G.; SCHEUENSTUHL, M. C. B. (Orgs.). Águas do Brasil: análises estratégicas. Rio de Janeiro: ABC, 2011. v. 1. p. 144-164, 2011.

INSTITUTO BRASILEIRO DE GEOGRAFIA E ESTATÍSTICA - IBGE. Pesquisa Nacional de Saneamento Básico 2008. Disponível em <http://www.ibge.gov.br/home/estatistica/populacao/condicaodevida/pnsb2008/defaultt abpdf.shtm>. Acesso em: 10 fevereiro 2015.

INSTITUTO MINEIRO DE GESTÃO DAS ÁGUAS E DESENVOLVIMENTO SUSTENTÁVEL - IGAM. Monitoramento da qualidade das águas superficiais no estado de Minas Gerais. 2013 Disponível em: http://www.igam.mg.gov.br/images/ stories/qualidade_aguas/2014/relatorio-aguas-superficiais-do-3o-trimestre-de-2013minas-gerais-1o-parte.pdf. Acesso em: 15 fevereiro 2015.

LIMA, G. M.; FREITAS, M. P. Avaliação qualitativa da potabilidade das águas de consumo humano dos poços outorgados e nascentes no perímetro urbano da cidade de Uberaba-MG. 2007. 70 p. Monografia (Graduação em Tecnologia em Gestão Ambiental) - Faculdades Integradas de Uberaba, Uberaba, 2007. 
MENEZES, J. P. C.; BERTOSSI, A. P. A; SANTOS, A. L.; NEVES, M. A. Qualidade da água subterrânea para consumo humano e uso agrícola no sul do estado do Espírito Santo. Reget. v. 17, n. 17. p. 3318 - 3326, 2013. http://dx.doi.org/10.5902/2236117010630

MOURA, R. S.; PELLI, A; TERRA, A. P. S; OKURA, M. H. Qualidade da água de minas em área urbana na cidade de Uberaba (MG). Revista Baiana de saúde pública. v. 33, n. 2, p. 231-242, 2009.

NAKAMURA, C. Y.; MARQUES, E.; VILELA, P.; ODA, T.; LIMA, L.; COSTA, R. et al. Avaliação da qualidade da água subterrânea no entorno de um aterro sanitário. Águas Subterrâneas. v.28, n.2. p.28-40, 2014. http://dx.doi.org/10.14295/ras.v28i2.27399

NASCIMENTO, S.; BARBOSA, J. S. F. Qualidade da água do aquífero freático no alto cristalino de salvador, Bacia do Rio Lucaia, Salvador, Bahia. Revista Brasileira de Geociências. v. 35, n. 4, p.543-550, 2005.

PERCEBON, C. M.; BITTENCOURT, A. V. L; ROSA FILHO, E. F. Diagnóstico da temperatura das águas dos principais rios de Blumenau, SC. Boletim Paranaense de Geociências, n. 56, p. 7-19, 2005.

PERPÉTUO, E. A. Parâmetros de caracterização da qualidade das águas e efluentes industriais. São Paulo: CEPEMA-USP, 2014. 90p

SCORSAFAVA, M. A.; SOUZA, A.; STOFER, M.; NUNES, C. A.; MILANEZ, T. V. Avaliação físico-química da qualidade de água de poços e minas destinada ao consumo humano. Revista do Instituto Adolfo Lutz. v.69, n. 2, p.229-232, 2010.

SILVA, J. A. Tópicos de tecnologia de alimentos. São Paulo: Livraria Varela, 2000. 227 p.

SILVA, R. C. A.; ARAÚJO, T. M. Qualidade da água do manancial subterrâneo em áreas urbanas de Feira de Santana (BA). Ciências Saúde Coletiva, v. 8, n. 4, p.1010-1028, 2002.

SUHOGUSOFF, A. V.; HIRATA, R.; FERRARI, L. C. K. M. Water quality and risk assessment of dug wells: a case study for a poor community in the city of São Paulo, Brazil. Environmental Earth Sciences, v. 68, p. 899-910, 2013. http://dx.doi.org/10.1007/s12665-012-1971-x

UBÁ. Prefeitura Municipal. Plano de gestão dos serviços de abastecimento de água potável e de esgotamento sanitário do Município de Ubá - Relatório Técnico. Ubá, 2011. 89 p.

Von SPERLING, M. V. Introdução à qualidade das águas e ao tratamento de esgotos. 3. ed. Belo Horizonte: Departamento de Engenharia Sanitária e Ambiental; Universidade Federal de Minas Gerais, 2005. 243 p. 